Journal of Pharmaceutical Science and Medical Reseaarch (PHARMED), 1 (2), 2018, 5-9

Available online at: http://e-journal.unipma.ac.id/index.php/pharmed

ISSN 2614-4840 (print) ISSN 2614-6118 (online)

\title{
UPAYA PEMENUHAN KEBUTUHAN NUTRISI PADA ANAK DENGAN DEMAM TIFOID
}

\author{
Enggel Bayu Pratama \\ Prodi Ilmu Keolahragaan, Fakultas Ilmu Kesehatan dan Sains, Universitas PGRI Madiun, Indonesia \\ E-mail : enggel@unipma.ac.id
}

\begin{abstract}
Abstrak
Demam Tifoid adalah penyakit infeksi menyerang saluran pencernaan yang mengakibatkan berkurangnya masukan nutrisi bagi tubuh untuk proses penyembuhan anak. Tujuan pemenuhan kebutuhan nutrisi pada anak dengan demam tifoid agar tidak terjadinya komplikasi serta tercukupinya kebutuhan nutrisi untuk proses metabolisme tubuh yang meningkat akibat infeksi. Metode penelitian ini menggunakan metode penelitian studi kasus. Informan dalam penelitian ini adalah orang tua dan pasien anak dengan demam tifoid yang mengalami masalah pemenuhan kebutuhan nutrisi. Data diperoleh dari pemeriksaan fisik pada pasien, keluarga, perawat ruangan, dan catatan perkembangan pasien melalui observasi secara langsung. Hasil penelitian menunjukkan bahwa anak dengan demam tifoid dengan masalah pemenuhan kebutuhan nutrisi ditemukan adanya bibir kering pecah-pecah, konstipasi, mual, muntah, penurunan nafsu makan dan penurunan berat badan. Pada evaluasi yang diperoleh antara lain pasien dapat mempertahankan berat badan, adanya peningkatan nafsu makan, tidak ada mual, muntah, tanda malnutrisi dan didapatkan nilai normal pada pemeriksaan hemoglobin. Dari hasil analisis peningkatan asupan makan pada anak dengan demam tifoid dapat tercapai dengan adanya kerjasama antara petugas kesehatan dan keluarga dalam pelaksanaan program terapeutik dalam peningkatan intake makanan, pemantauan asupan nutrisi yang dilakukan setiap hari dengan pemeriksaan berat badan, pemeriksaan klinis, dan masukan diit, serta kolaborasi pemberian diit dan nutrisi parenteral. Untuk mengatasi masalah pemenuhan kebutuhan nutrisi pada anak dengan demam tifoid perlu dilakukan tindakan keperawatan yang komprehensif. Keterlibatan orang tua dalam pemenuhan kebutuhan nutrisi pada pasien anak sangat berpengaruh dalam keberhasilan pemenuhan kebutuhan nutrisi anak selama di rumah sakit.
\end{abstract}

Kata Kunci : Demam Tifoid, nutrisi, anak.

\begin{abstract}
Typhoid fever is an infectious disease that attacks the digestive tract which results in reduced input of nutrients for the body for the healing process of children. The purpose of fulfilling the nutritional needs of children with typhoid fever so that complications do not occur and adequate nutritional needs for the body's metabolic processes are increased due to infection. This research method uses a case study research method. The informants in this study were parents and pediatric patients with typhoid fever who had problems fulfilling nutritional needs. Data obtained from physical examination on patients, family, nurse room, and patient development records through direct observation. The results showed that children with typhoid fever with problems in fulfilling nutritional needs found chapped dry lips, constipation, nausea, vomiting, decreased appetite and weight loss. In evaluations obtained, among others, patients can maintain weight, increase appetite, no nausea, vomiting, signs of malnutrition and get normal values on hemoglobin examination. From the results of an analysis of the increase in food intake in children with typhoid fever can be achieved by the collaboration between health workers and families in the implementation of therapeutic programs in increasing food intake, monitoring nutritional intake every day with weight checks, clinical examinations, and diit input, and collaboration in diit administration and parenteral nutrition. To overcome the problem of fulfilling nutritional needs in children with typhoid fever, comprehensive nursing action needs to be done. Parental involvement in meeting nutritional needs in pediatric patients is very influential in the successful fulfillment of children's nutritional needs while in hospital.
\end{abstract}

Keywords: Typhoid Fever, nutrition, children. 
Journal of Pharmaceutical Science and Medical Reseaarch (PHARMED), 1 (2), 2018, 5-9

Available online at: http://e-journal.unipma.ac.id/index.php/pharmed

ISSN 2614-4840 (print) ISSN 2614-6118 (online)

\section{PENDAHULUAN}

Kebutuhan nutrisi merupakan kebutuhan yang sangat penting dalam membantu proses pertumbuhan dan perkembangan pada anak, mengingat manfaat nutrisi dalam tubuh dapat membantu proses pertumbuhan dan perkembangan anak (Hidayat, 2008). Salah satu faktor ekologi yang mempengaruhi terganggunya pemenuhan kebutuhan nutrisi adalah dari faktor infeksi atau penyakit. Penyakit infeksi yang sering diderita oleh anak ialah demam tifoid yang merupakan penyakit infeksi akut yang terdapat pada saluran pencernaan.

Menurut Depkes RI disebutkan bahwa demam tifoid banyak diderita oleh anak usia 2-19 tahun. Prevalensi tertinggi pada anak usia 5-9 tahun karena pada usia ini anak cenderung memiliki aktifitas fisik yang banyak, dan kurang memperhatikan pola makan, cenderung memilih makan di luar rumah, atau jajan di tempat lain, kurang memperhatikan kebersihan perseorangannya yang mungkin diakibatkan karena ketidaktahuan anak bahwa dengan jajan makanan sembarang dapat menyebabkan tertular penyakit demam tifoid (Soegijanto, 2007).

Demam tifoid merupakan penyakit infeksi yang terjadi pada usus halus yang disebabkan oleh Salmonella thypi. Penyakit demam tifoid dapat ditularkan melalui makanan, mulut atau minuman yang terkontaminasi oleh kuman Salmonella thypi. Selanjutnya kuman tersebut akan menembus usus dan masuk ke peredaran darah melalui aliran limfe dan menyebar ke seluruh tubuh dalam sistem retikuloendotelial yaitu hati dan limfa, kemudian kuman berkembang biak dan masuk ke peredaran darah kembali. Kuman menyerang pada daerah usus ileum bagian distal, di mana pada minggu pertama dapat terjadi hiperflasi plak peyer, kemudian pada minggu kedua dapat terjadi nekrosis, pada minggu ketiga dapat terjadi ulserasi, dan selanjutnya pada minggu keempat terjadi penyembuhan ulkus yang dapat meninggalkan sikatrik yang memudahkan terjadi perdarahan hingga perforasi (Hidayat, 2008).

Pasien demam tifoid bisa terjadi gangguan kesadaran dari apatis, somnolen sampai delirium disamping anoreksia dan demam lama. Keadaan ini menyebabkan kurangnya masukan nutrisi sehingga kebutuhan nutrisi yang penting untuk masa penyembuhan berkurang pula, dan memudahkan timbulnya komplikasi (Hidayat, 2008). Apabila gangguan pemenuhan kebutuhan nutrisi pada anak dengan demam tifoid berlangsung terus menerus tidak terpenuhi dalam waktu cukup lama serta tidak ditangani secara serius, maka kekurangan nutrisi akan bertambah berat sehingga mengakibatkan penurunan berat badan dan sistem kekebalan tubuh sehingga memudahkan proses infeksi oleh agen penginfeksi, hal tersebut dapat mempengaruhi proses pertumbuhan dan perkembangan anak. Oleh karena itu anak yang menderita demam tifoid perlu dilakukan perawatan lebih lanjut di pusat pelayanan kesehatan. Kompetensi serta pengetahuan yang kuat mengenai penanganan masalah nutrisi pada anak dengan demam tifoid mampu memberikan penanganan yang berkualitas.

Berdasarkan hal-hal yang telah diuraikan dalam latar belakang masalah di atas, mendorong penulis untuk menyusun karya tulis dengan judul "Upaya Pemenuhan Kebutuhan Nutrisi Pada Anak dengan Demam Tifoid".

\section{METODELOGI PENELITIAN}

Rancangan yang digunakan dalam penelitian ini adalah studi kasus. Menurut Setiadi (2007), studi kasus merupakan prosedur penelitian yang dilaksanakan dengan cara meneliti suatu permasalahan melalui suatu kasus yang terdiri dari unit tunggal. Unit tunggal disini dapat berarti satu orang, kelompok penduduk yang terkena suatu masalah. Unit yang menjadi masalah tersebut secara mendalam dianalisa baik dari segi yang berhubungan dengan kasusnya sendiri, faktor resiko, yang mempengaruhi, kejadian yang berhubungan dengan kasus maupun tindakan dan reaksi dari kasus terhadap suatu perlakuan atau pemaparan tertentu. Lokasi pengambilan studi kasus adalah di Ruang Irna IV RSUD Dr. Sayidiman Magetan. Waktu penelitian untuk studi kasus dimulai bulan Maret 2017-Agustus 2017. Subyek data yang dipilih dalam studi kasus ini adalah anak usia prasekolah (3-5) dan usia sekolah (6-12) yang menderita demam tifoid yang rawat inap hari pertama dengan mual dan muntah, porsi makan yang tidak habis serta mengalami penurunan berat badan yang didampingi ibu (keluarganya).

Metode pengumpulan data yang digunakan adalah sebagai berikut Wawancara, Observasi dan dokumentasi. Bahan pengumpulan datanya antara lain buku catatan, alat tulis, pengukuran dengan alat (thermometer, jam tangan, stetoskope, timbangan, alat ukur lila, metline, mikrotiase/ alat untuk mengukur tinggi badan), dengan adanya alat tersebut peneliti dapat mengetahui keadaan umum pasien dan dapat membantu dari hasil pengamatan atau observasi peneliti. Sedangkan tehnik yang digunakan adalah inspeksi, auskultasi, palpasi, dan perkusi. 
Journal of Pharmaceutical Science and Medical Reseaarch (PHARMED), 1 (2), 2018, 5-9

Available online at: http://e-journal.unipma.ac.id/index.php/pharmed

ISSN 2614-4840 (print) ISSN 2614-6118 (online)

a. Inspeksi, merupakan kegiatan melihat atau memperhatikan secara seksama status kesehatan pasien. Kunci keberhasilan inspeksi adalah dengan mengetahui apa yang harus dilihat atau diamati.

b. Palpasi, merupakan jenis pemeriksaan fisik dengan cara meraba atau merasakan kulit pasien untuk mengetahui struktur yang ada dibawah pasien dan dilakukan untuk memperkuat hasil inspeksi.

c. Perkusi, merupakan jenis pemeriksaan fisik dengan cara mengetuk secara pelan jari tengah menggunakan jari yang lain untuk menentukan posisi, ukuran dan konsistensi struktur suatu organ tubuh. Untuk memperoleh hasil perkusiyang akurat diperlukan keterampilan teknis dan interpretasi bunyi.

d. Auskultasi, merupakan langkah pemeriksaan fisik dengan menggunakan stetoskop yang memungkinkan pemeriksa mendengar bunyi yang keluar dari rongga tubuh pasien. Auskultasi ini dilakukan untuk mendapatkan data tentang kondisi jantung, paru, dan saluran pencernaan.

\section{HASIL DAN PEMBAHASAN}

Pada banyak kasus sample penelitian, klien mengatakan nyeri pada perut kuadran kanan atas, merasa mual dan muntah saat makan, serta mengalami penurunan berat badan dari $48 \mathrm{~kg}$ menjadi $46 \mathrm{~kg}$. Keadaan tersebut sesuai dengan teori yang ada di tinjauan pustaka. Penurunan berat badan bisa disebabkan kurangnya asupan nutrisi karena penurunan nafsu makan, mual dan muntah.

Terdapat beberapa intervensi yang dapat disusun untuk mengatasi masalah nutrisi pada pasien anak dengan demam tifoid yaitu sajikan makanan dalam keadaan hangat dan menarik, anjurkan makan porsi kecil dan sering, hindari makanan buah-buahan dan hindari diit tinggi serat, timbang berat badan secara teratur, beri umpan balik positif pada anak yang menunjukkan peningkatkan nafsu makan, beri penjelasan kepada anak dan orang tua tentang pentingnya nutrisi bagi penyembuhan penyakit, beri pendidikan kepada orang tua mengenai sakit anaknya agar menerapkan diit yang tepat, kolaborasi dalam pemberian diit dan cairan parenteral. Tindakan yang dilakukan antara lain :

1. Menganjurkan makan sedikit tapi sering, meningkatkan intake cairan dan nutrisi, serta menimbang BB secara teratur

Pada saat sebelum dilakukan tindakan,

klien mengatakan merasa mual dan makan hanya habis 4-5 sendok, terdapat tanda-tanda klinis seperti turgor kulit menurun, mukosa kering, dan bibir pecah-pecah, bising usus 13 $\mathrm{x} /$ menit, serta $\mathrm{BB}$ sekarang $46 \mathrm{~kg}$. Setelah dilakukan tindakan menganjurkan makan sedikit tapi sering rasa mual yang dirasakan anak berangsur-angsur berkurang, menganjurkan meningkatkan intake cairan dan nutrisi anak mampu menghabiskan porsi makan yang disediakan RS dan tidak ada tanda-tanda klinis dehidrasi dan kekurangan nutrisi, menimbang BB secara teratur diketahui tercapai tidaknya penatalaksanaan nutrisi klien. Pada hari kedua sampai keempat, klien dan orang tua masih kooperatif dan bersedia untuk melaksanakan tindakan yang sudah dianjurkan perawat dan asupan makan klien berangsur-angsur meningkat.

Seperti yang dijelaskan oleh Hidayat (2008) bahwa pemberian memberikan makan sedikit tapi sering agar jumlah asupan terpenuhi, pemberian nutrisi dalam bentuk lunak untuk membantu nafsu makan, memonitor berat badan, adanya bising usus dan status gizi, pemberian ekstrak susu dan diit MLTKTP merupakan beberapa tindakan untuk penatalaksanaan ketidakseimbangan nutrisi dengan meningkatkan asupan makan untuk mencukupi kebutuhan nutrisi klien yang kurang.

Mual, muntah, dan penurunan nafsu makan karena terjadi peradangan pada usus halus dan juga dapat menyebabkan malabsorbsi sehingga kebutuhan nutrisi tidak terpenuhi dan terjadi penurunan berat badan. Sehingga perlu dilakukan tindakan memberikan makan tapi sering dimana tindakan tersebut efektif pada saat masa akut hingga mencapai batas toleransi klien untuk mengkonsumsi makanan seperti biasa. Menimbang BB secara teratur, tidak memberikan pengaruh terhadap peningkatan asupan makan klien namun akan memberi catatan penurunan atau kenaikan BB yang dapat digunakan untuk acuan tercapai atau tidaknya penatalaksanaan nutrisi yaitu dengan mempertahankan BB klien.

2. Anjurkan Untuk Bedrest dan Membatasi Aktifitas

Pada saat sebelum dilakukan tindakan yaitu klien merasakan demam, kepala pusing dan nyeri pada perut serta klien terlihat lemas dan lesu. Kien mengatakan demam, kepala pusing cenut-cenut dan kualitas nyeri hilang timbul. Setelah dilakukan tindakan pada hari pertama, klien masih merasa lemas, lesu, demam, sakit kepala, dan nyeri perut. Pada hari kedua sampai keempat klien masih patuh 
Journal of Pharmaceutical Science and Medical Reseaarch (PHARMED), 1 (2), 2018, 5-9

Available online at: http://e-journal.unipma.ac.id/index.php/pharmed

ISSN 2614-4840 (print) ISSN 2614-6118 (online)

terhadap anjuran perawat untuk bedrest, dan klien mengatakan demam berangsur-angsur turun dan tidak lagi merasa pusing atau nyeri perut serta tidak merasa lemas dan lesu.

Hal ini didukung dengan pernyataan Riyadi (2010) bahwa pada anak dengan demam tifoid tirah baring atau bedrest dan pembatasan aktifitas perlu dilakukan selama demam karena dapat mencegah komplikasi seperti perdarahan usus dan perforasi usus.

Tindakan dengan menganjurkan klien untuk bedrest dan membatasi aktifitas tetap diperlukan untuk mengurangi dampak buruk yang dapat disebabkan apabila klien beraktifitas secara mandiri. Selain itu, tindakan tersebut bertujuan mengurangi kebutuhan metabolisme tubuh yang meningkat akibat proses infeksi dimana kebutuhan juga akan bertambah apabila klien banyak melakukan aktifitas. Karena itu, tindakan bedrest dan pembatasan aktifitas perlu dilakukan sehingga tidak muncul kemungkinan terjadinya komplikasi yang dapat memperparah penyakitnya. Diperlukan juga kepatuhan klien untuk tercapainya tujuan dari tindakan bedrest.

\section{Health Education}

Sebelum diberikan Health Education, orang tua klien cemas dan menanyakan kondisi anaknya. Orang tua kurang mengetahui tentang kondisi anaknya dan hal apa yang harus dilakukan saat klien mual dan muntah dan keluhan lainnya seperti nyeri perut, pusing, dan panas tinggi. Setelah dilakukan tindakan, orang tua tidak cemas lagi, mengatakan paham tentang kondisi anaknya, serta siap dan bersedia terlibat dalam program terapeutik klien.

Pemberian Health Education atau bimbingan antisipasi pada klien tidak mengurangi keluhan yang dirasakan klien, karena keluhan masih terasa meskipun sudah berangsur-angsur berkurang. Namun informasi tersebut dapat membuat klien dan orang tua menjadi lebih tenang dan tidak merasa cemas setelah mengetahui tentang hubungan demam tifoid dan pengaruhnya terhadap asupan nutrisi serta tindakan yang dapat dilakukan untuk mengoptimalkan asupan nutrisi.

Health Education perlu diberikan pada orang tua dan klien yang belum pernah mengalami sakit demam tifoid sebelumnya karena belum dapat mengidentifikasi mual, muntah ataupun penyebabnya, tindakan yang dapat dilakukan untuk mencukupi asupan nutrisi klien, serta hal yang dapat mempercepat atau memperburuk penyembuhan. Pemahaman klien dan orang tua yang baik mengenai kondisinya akan mengurangi tingkat kecemasan dan menghasilkan kepatuhan diit. Health Education juga perlu diberikan pada klien yang sudah pernah mengalami demam tifoid, dan memberikan anjuran untuk menghindari kambuhnya penyakit.

4. Pemberian Farmakoterapi

Wijaya, Andra dan Yessie (2013) menyebutkan bahwa farmakoterapi yang tepat untuk demam tifoid yaitu kloramfenikol. Terapi yang didapatkan klien pada hari pertama yaitu paracetamol, cefotaxim dan ranitidine, kemudian terapi antibiotik pada hari kedua sampai keempat diganti kloramfenikol. Setelah pemberian terapi farmakologis, klien menunjukkan penurunan demam, rasa mual, dan rasa sakit pada perut yang signifikan baik. Penurunan tersebut juga sama drastisnya pada hari kedua sampai keempat.

\section{KESIMPULAN}

Dari hasil pembahasan antara tinjauan teori dan tinjauan kasus diperoleh suatu kesimpulan sebagai berikut:

1. Karakteristik yang didapat pada anak dengan demam tifoid dengan masalah nutrisi adalah nyeri perut, demam \pm 5 hari, mual dan muntah saat makan, mengalami penurunan nafsu makan.

2. Upaya yang dilakukan dalam memenuhi kebutuhan nutrisi klien antara lain menganjurkan makan sedikit tapi sering \& menganjurkan meningkatkan intake cairan dan nutrisi untuk mencukupi kebutuhan nutrisi tubuh, menimbang $\mathrm{BB}$, anjuran bedrest dan membatasi aktifitas, pemberian Health Education, kolaborasi dengan tim gizi yaitu pemberian diit MLTKTP, dan pemberian terapi farmakologis, yaitu Kloramfenikol akan mengurangi penyebab infeksi, ranitidine untuk mengurangi rasa mual, dan paracetamol untuk menurunkan demam. Tindakan keperawatan yang mempunyai pengaruh lebih terhadap masalah nutrisi yaitu pemberian makan sedikit tapi sering, karena dapat mengatasi masalah utama yang menyebabkan asupan nutrisi kurang yaitu mual dan muntah. Serta tindakan keperawatan dengan mempersiapkan orang tua untuk berperan dalam mencukupi asupan nutrisi anaknya. Terapi farmakologis juga berperan dalam 
Journal of Pharmaceutical Science and Medical Reseaarch (PHARMED), 1 (2), 2018, 5-9

Available online at: http://e-journal.unipma.ac.id/index.php/pharmed

ISSN 2614-4840 (print) ISSN 2614-6118 (online)

proses pemenuhan kebutuhan nutrisi.

Karena dapat mengurangi keluhan yang timbul.

4. Upaya pemenuhan kebutuhan nutrisi telah tercapai dalam 4 hari, respon klien sama dengan hasil yang diharapkan yaitu tidak merasa mual dan muntah saat makan, asupan nutrisi adekuat, mukosa bibir lembab, bibir tidak pecah-pecah, turgor kulit baik, klien dapat mempertahankan berat badan serta nilai laboratorium $\mathrm{Hb}$ dalam batas normal. Klien dan orang tua mengerti tentang penyebab dan hubungan antara demam tifoid dan pengaruhnya terhadap nutrisi, faktor yang memperparah dan mempercepat penyembuhan, tindakan yang tepat untuk mengoptimalkan aspan nutrisi, serta anjuran untuk menghindari kambuhnya penyakit. Orang tua siap dan memiliki kesadaran akan pentingnya kebutuhan nutrisi anaknya sehingga dapat bersabar dan telaten dalam memenuhi kebutuhan nutrisi anaknya.

\section{DAFTAR PUSTAKA}

Hidayat, Alimul.A. (2008). Pengantar Ilmu Keperawatan Anak. Jilid 1. Jakarta : Salemba Medika.

Riyadi, Sujono dan Suharsono. (2010). Asuhan Keprawatan Pada Anak Sakit. Yogyakarta : Gosyen Publishing.

Riyadi, Sujono dan Suharsono. (2010). Asuhan Keprawatan Pada Anak Sakit. Yogyakarta : Gosyen Publishing.

Soegijanto, et all (2002). Ilmu Penyakit Anak: Diagnosa \& Penatalaksanaan. Jakarta : Salemba Medika.

Setiadi, (2007). Konsep dan Penulisan Riset Keperawatan. Jakarta : Graha Ilmu.

Wijaya, Andra Saferi, dan Putri, Yessie Mariza. (2013). Keperawatan Medikal Bedah. Jakarta : Medical Book. 
Journal of Pharmaceutical Science and Medical Reseaarch (PHARMED), 1 (2), 2018, 5-9

Available online at: http://e-journal.unipma.ac.id/index.php/pharmed

ISSN 2614-4840 (print) ISSN 2614-6118 (online) 